\title{
A Rare Case of Drug-induced Vasculitis in Out-patient Department
}

\author{
Abhishek Sharma1, Gulnaz Bano', Abdul Malik ${ }^{3}$ \\ From ${ }^{1}$ Quality Control Officer, Department of Quality Control and Assurance, Hakeem Abdul Hameed Centenary Hospital and Hamdard Institute \\ of Medical Sciences and Research, New Delhi, India, ${ }^{2}$ Faculty of Pharmacy, Department of Pharmacology and Pharmacy Practice, School of \\ Pharmaceutical Education and Research, New Delhi, India, ${ }^{3}$ Clinical Pharmacist (Infection Control), Department of Clinical Pharmacy, Artemis \\ Hospital, New Delhi, India
}

\begin{abstract}
Drug-induced vasculitis can be defined as inflammation of blood vessels triggered by a spectrum of drugs. It presents not only with a localized skin rash but also may involve the internal organ systems, including the gastrointestinal tract, kidneys, lungs, central nervous system, and joints. Here, we report the case of a 60 -year-old woman who developed purpuric pruritic rashes on bilateral lower limbs and buttocks after the ingestion of sulphasalazine. The patient took the prescribed regimen for 14 days while experiencing an adverse drug reaction. At the follow-up visit, the patient was admitted and treated with methylprednisolone monotherapy with $32 \mathrm{mg} / \mathrm{day}$ for the first 3 days and after that, methylprednisolone $16 \mathrm{mg}$ for the next 3 days. The rashes resolved after 6 days. Clinicians should ascertain the patient knowledge of how and when to obtain urgent care as the patient may experience ill effects after taking prescribed treatment. Timely advice may save patients' costs of admission and treatment to manage adverse events.
\end{abstract}

Key words: Adverse drug reaction, Adverse event, Drug-induced vasculitis, Purpuric pruritic rashes, Sulphasalazine

$\mathrm{V}$ asculitis is defined as an inflammatory cell infiltration and destruction of blood vessels. Vasculitis is categorized as primary, secondary, incidental, and drug-induced. Primary vasculitis is idiopathic (cutaneous leukocytoclastic angiitis, Wegener's granulomatosis), whereas, secondary vasculitis is caused due to manifestation of connective tissue diseases, infections, adverse drug eruptions, or a paraneoplastic phenomenon [1]. Incidental vasculitis can be attributed to the pathologic process such as traumatic ulceration or diffuse neutrophilic infiltration and drug-induced vasculitis is an inflammatory vasculitis in which a drug is causally related to the disease when other types of vasculitis have been excluded [2]. It commonly appears on the lower extremities or pressuredependent areas of the skin as erythematous or violaceous lesions. Lesions ranging in size from a pinpoint to several centimeters often are macular but may be palpable with variable morphology. Urticarial lesions may coexist with purpura and in severe cases, development of vesicular, bullous, hemorrhagic, ulcerating, or necrotic lesions may be seen. Systemic symptoms such as burning, stinging, malaise, arthralgia, and fever also may be present [3].

This case report focuses on how gaps in communication or no disclosure of information in an out-patient department (OPD)

\section{Access this article online}

Received - 09 December 2021

Initial Review - 27 December 2021

Accepted - 03 January 2022

DOI: $10.32677 /$ ijcr.v7i12.3229 prescription of "how and when to obtain urgent care" leads to the serious error of commission, diagnosis, and treatment with druginduced cutaneous vasculitis.

\section{CASE REPORT}

A 60-year-old female came in the medicine OPD with complaints of pain in the abdomen for 2 days and generalized body pain, restlessness, and dizziness for 1 week. She also complained of purpuric pruritic rashes, itching over the bilateral lower limb, and buttocks on the $14^{\text {th }}$ day after taking whole 2 weeks regimen of Tab Hydroxychloroquine $200 \mathrm{mg}$ and Tab Sulfasalazine 500mg twice a day for 2 weeks. The event started on the $1^{\text {st }}$ day (the day when the patient took the culprit drug) after taking a regimen for polyarthralgia (Figs. 1-3). Sulfasalazine and hydroxychloroquine were stopped by the provider. The patient has a past medical history of hypertension and hypothyroidism.

On examination, the patient was having a weight of $52 \mathrm{~kg}$ and a height of $4 \mathrm{Ft} 11$ Inches. The vitals were checked and found stable with a blood pressure of 110/70 $\mathrm{mmHg}$, pulse rate of 78/ min, $\mathrm{SpO}_{2}$ of $98 \%$, and respiratory rate of $20 / \mathrm{min}$.

2D Echo was normal and ultrasonography showed coarse echotexture of the liver and hepatomegaly.

Correspondence to: Dr. Abhishek Sharma, Doctor of Pharmacy (Pharm.D), MBA (Hospital Administration), Quality Control Officer, Hakeem Abdul Hameed Centenary Hospital, Jamia Hamdard, New Delhi - 110 062, India. Phone Number: +918454960417. E-mail: scientist.abhi12@gmail.com

(C) 2022 Creative Commons Attribution-NonCommercial 4.0 International License (CC BY-NC-ND 4.0). 


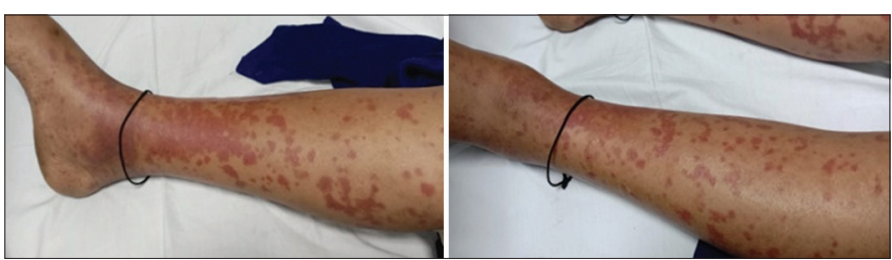

Figure 1: Rashes at the time of admission in hospital in medicine ward (follow-up day)

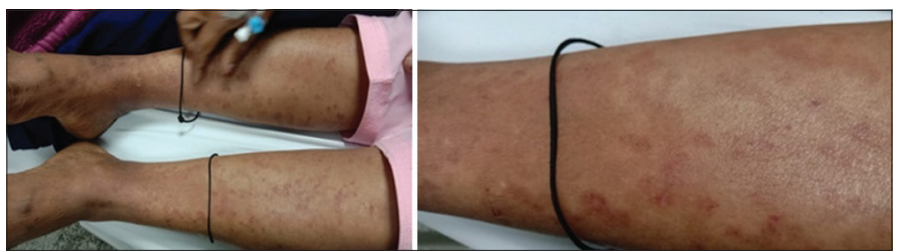

Figure 2: Condition after 3 days of taking methylprednisolone ( $3^{\text {rd }}$ day)

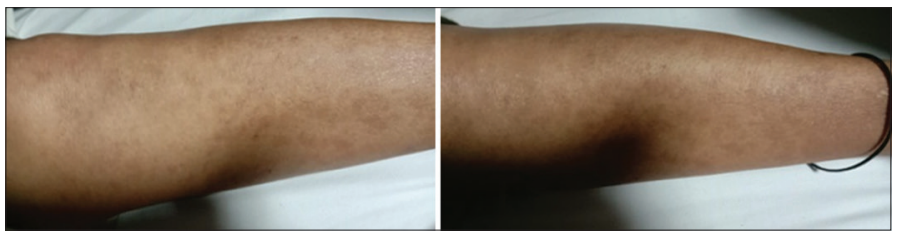

Figure 3: Rashes resolved after 6 days of taking methylprednisolone $\left(6^{\text {th }}\right.$ day)

Laboratory investigation results were as follows: Thyroidstimulating hormone level was $6.19 \mathrm{mIU} / \mathrm{L}$, hemoglobin was $9 \mathrm{~g} / \mathrm{dl}$, total leukocyte count was $9600 / \mathrm{microL}$, and platelet count was $368000 /$ microL. The liver function test showed total bilirubin was $0.58 \mathrm{mg} / \mathrm{dl}$, albumin was $3.8 \mathrm{~g} / \mathrm{dl}$, creatinine was $0.98 \mathrm{mg} / \mathrm{dl}$, urea was $23.9 \mathrm{mg} / \mathrm{dl}$, serum glutamic-oxaloacetic transaminase was $24 \mathrm{IU} / \mathrm{L}$, serum glutamic pyruvic transaminase was $26 \mathrm{IU} / \mathrm{L}$, and alkaline phosphatase was $176 \mathrm{IU} / \mathrm{L}$. Urine routine examination showed the presence of pus cells 8-10/ hpf. Anti-cyclic citrullinated peptide was normal, rheumatoid arthritis factor was $8.61 \mathrm{IU} / \mathrm{ml}$-negative, HCV was negative, and C-reactive protein (CRP) was negative. Random blood sugar was also in the normal range. Erythrocyte sedimentation rate (ESR) was elevated $55 \mathrm{~mm} / 1^{\mathrm{sth}}$ (normal range 0-15). AntiNuclear Antibody (Immunofluorescent) was positive (fluorescent intensity + at cut off). End titer 1:160.

The treatment was started for drug-induced vasculitis as the final diagnosis. Treatment during 6 days of the hospital stay was Diphenyhydramine, white-soft paraffin, and light liquid paraffin lotion, Tablet methylprednisolone $32 \mathrm{mg}$ once a day for 3 days then, $16 \mathrm{mg}$ once a day for 3 days, Tablet hydroxyzine $25 \mathrm{mg}$ twice a day for 6 days, and clobetasol ointment $0.05 \%$ local application twice a day for 6 days.

\section{DISCUSSION}

Systemic drug-induced syndrome develops only in a minority of patients when the treatment with the drug is prolonged, on the other side, cutaneous vasculitis occurs quite commonly. The most frequent symptoms at onset are arthralgia, myalgia, and skin rash.
Early withdrawal of the culprit drug usually leads to complete recovery while more advanced disease and the late withdrawal of the drug may require the usage of corticosteroid and/or immunesuppression therapies [4].

Several cases of drug-induced vasculitis resolve within weeks after the withdrawal of the culprit drug and only a few cases, mainly those with multi-organ system involvement, may continue for months [2]. Few tests or investigations are required for the detection of the cause of dermal vasculitis such as red blood cells, white blood cells, urinalysis, platelet counts, albumin, creatinine, and chest X-ray. If suspected, blood cultures should be obtained [5]. CRP and ESR are usually elevated in patients with drug-induced vasculitis. On diagnostic workup, they are not sufficiently sensitive but non-specific in making a diagnosis, because detection of AntiNeutrophilic Cytoplasmic Autoantibody might serve as a warning of the possibility of drug-induced vasculitis [6].

There is no standard approach to the treatment of drug-induced dermal vasculitis. Treatment should be based on the individual assessment of patients with drug-induced vasculitis. The primary step involves the discontinuation of the offending medication [6]. Glucocorticoids or immunosuppressive therapy should be given. High-dose corticosteroid ( $1 \mathrm{mg} / \mathrm{kg} /$ day $)$ or intravenous "pulse" therapy (methylprednisolone $1 \mathrm{~g} /$ day-3 days) may be administered to patients with life-threatening conditions. A typical starting dose of prednisolone is $40-60 \mathrm{mg}$ /day orally for 4 weeks [7]. During the hospital stay, the patient had been given supportive care and the offending drug (Sulphasalazine) was already discontinued prior to the admission and methylprednisolone $32 \mathrm{mg}$ was orally administered to the patient for the first 3 days of admission. After 6 days of this therapy, the patient skin rashes were almost resolved with minor residuals. The patient was discharged after observation of 1 week.

\section{CONCLUSION}

This case report describes a drug reaction to sulfasalazine which presented purpuric pruritic rashes on bilateral lower limbs and buttocks. In a majority of instances, improvement occurs with the withdrawal of the offending drug, however, a significant proportion may also require additional immunosuppressive therapy with corticosteroids alone, or with other agents such as cyclophosphamide. In this case, methylprednisolone therapy had been given for 6 days and rashes were resolved. Health care providers should be aware of the propensity of drugs to cause vascular manifestations.

\section{REFERENCES}

1. Carlson JA, Ng BT, Chen KR. Cutaneous vasculitis update: Diagnostic criteria, classification, epidemiology, etiology, pathogenesis, evaluation and prognosis. Am J Dermatopathol 2005;27:504-28

2. Merkel PA. Drug-induced vasculitis. Rheum Dis Clin North Am 2001;27:849-62.

3. Dipro JT, Talbert RL, Yee GC, Matzke GR, Wells BG, Posey ML. A Textbook of Pharmacotherapy. A Pathophysiologic Approach. $5^{\text {th }}$ ed. United States: McGraw-Hill Education Publisher; 2002. p. 1709.

4. Wiik A. Drug-induced vasculitis. Curr Opin Rheumatol 2008;20:35-9. 
5. Gota CE, Calabrese LH. Diagnosis and treatment of cutaneous leukocytoclastic vasculitis. Int J Clin Rheumatol 2013;8:49-60.

6. Radić M, Kaliterna MD, Radić J. Drug-induced vasculitis: A clinical and pathological review. Neth J Med 2012;70:12-7.

7. Miller A, Chan M, Wiik A, Misbah SA, Luqmani RA. An approach to the diagnosis and management of systemic vasculitis. Clin Exp Immunol 2010;160:143-60.
Funding: None; Conflicts of Interest: None Stated.

How to cite this article: Sharma A, Bano G, Malik A. A rare case of drug-induced vasculitis in out-patient department. Indian J Case Reports. 2021;7(12):544-546. 